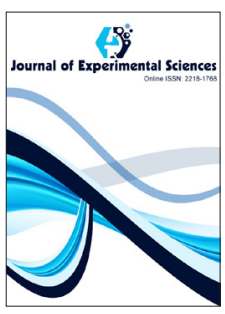

ISSN: $2218-1768$

Received: August 13, 2020 Accepted: October 18, 2020 Published: November 07, 2020

*Corresponding Author: M. Manjur Shah, Email:mmanjurshah@gmail. com

\section{Larvicidal activity of some selected medicinal plant extracts against the vector of filariasis}

\author{
A. B. Umar, A. H. Dankaka, M. Manjur Shah* \\ Department of Biological Sciences, Yusuf Maitama Sule University, Kano, Nigeria
}

\begin{abstract}
The present study assessed the role of larvicidal activities of hexane, ethyl acetate and methanol dried leaf and bark extracts of Ocimum gratissimum, Gleditsia triacanthos, Eucalyptus sglobulus and Azadirachta aindica against the fourth instar larvae of filariasis vector, Culex quinquefasciatus mosquito (Diptera: Culicidae). Larvicidal activities of four medicinal plant extracts were studied in the range of 4.69 to $1000 \mathrm{mg} / \mathrm{l}$ in the laboratory bioassays against early $4^{\text {th }}$ instar larvae of Culex quinquefasciatus. The mortality data were subjected to probit analysis to determine the lethal concentrations $\left(\mathrm{LC}_{50}\right.$ and $\left.\mathrm{LC}_{90}\right)$ to kill 50 and 90 per cent of the treated larvae of the respective species. All plant extracts showed moderate effects after $24 \mathrm{~h}$ of exposure; however, the highest toxic effect of leaf methanol extract of Ocimum gratissimum, bark ethyl acetate extract of Eucalyptus globulus, methanol extract of Azadirachta indicia and methanol bark extract of Gleditsia triacanthos against the larvae of Culex quinquefasciatus with $\mathrm{LC}_{50}=43.00,41.02$, 40.12 and $20.36 \mathrm{mg} / 1 ; \mathrm{LC}_{90}=278.32,218.72,215.01$ and $86.29 \mathrm{mg} / \mathrm{l}$ respectively. The result of findings shows that leaf and bark extract of G. tricantha, A .indica, O. gratissimum and E.globulus can be developed as ecofriendly larvicides.
\end{abstract}

KEYWORDS: Culex quinquefasciatus, medicinal plant, extracts, larvicide

\section{INTRODUCTION}

Mosquitoes are the major vector of filariasis and play an important role in spreading of vector-borne diseases like malaria, dengue, chikungunya and Japanese encephalitis which leads to cause thousands of deaths per year [1]. C. quinquefasciatus is a vector of lymphatic filariasis, (tropical disease) which accounted 120 million people infected worldwide, and 44 million people having common chronic manifestation. According to World Health Organization (WHO) estimates, globally about 90 million people are infected with $W$. bancrofti and ten times more peoples are at the risk of being infected. So far, 25 million people harboring microfilaria and 19 million people suffering from filarial disease manifestations were recorded from India [2]. The controlling of mosquito populations using chemical insecticides had some advantages viz. their speedy action and easy application. With the continuous use of chemical insecticides, the mosquitoes are becoming resistant. Alternatively, natural pesticides (especially from plants), act as more potential agents for mosquito vectors. Aromatic plants and their essential oils are best sources of many active compounds for multipurpose uses. Plant based phytochemicals having mosquitocidal properties are now recognized as potent alternative insecticides to replace synthetic insecticides [3]. Previously, many naturally occurring chemicals have been reported to influence mosquito oviposition [4], act as general toxicant, growth and reproductive inhibitors, repellents and oviposition-deterrent [5] essential oils isolated from Cinnamomum zeylanicum, Zingiber officinale and Rosmarinus officinalis showed oviposition-deterrent and repellent activities against A. stephensi, A. aegypti, and C. quinquefasciatus [6]. Another plant Cipadessabaccifera extract showed adulticidal activity against selected three mosquito vectors [7]. The present investigation will chose to study the mosquitocidal activities of G. tricantha, A. indica, E. globulus and O. gratissimum which are traditional medicinal plants. The essential oils obtained from leaves and stems of this plants were used as remedy for several health problems like fever, throat inflammations, ears or eyes, stomach pain, diarrhea, skin diseases [8]. Considering the above information's the present investigation deals with the use of G. tricantha, A. indica, E. globulus and O. gratissimum plant extracts for controlling Culex quinquefasciatus mosquito vector (Diptera: Culicidae).

\section{MATERIALS AND METHODS}

\section{Plant Materials}

The fresh and healthy leaves of Ocimum gratissimum, Gleditsia triacanthos, Eucalyptus globulus and Azadirachta indica were

Copyright: $\odot$ The authors. This article is open access and licensed under the terms of the Creative Commons Attribution License (http://creativecommons.org/licenses/by/4.0/) which permits unrestricted, use, distribution and reproduction in any medium, or format for any purpose, even commercially provided the work is properly cited. Attribution - You must give appropriate credit, provide a link to the license, and indicate if changes were made. 
collected from Kano botanical garden (Latittude $-11.7794^{\circ} \mathrm{N}$, Longitude $-78.2034^{\circ} \mathrm{E}$ ), which is rich in floral biodiversity and indigenous plant populations.

\section{Preparation of Plant Extracts}

The leaf and bark were dried for 7-10 days in the shade at the environmental temperatures $\left(27-37^{\circ} \mathrm{C} /\right.$ day time $)$. The dried bark $(600 \mathrm{~g})$ and leaf $(700 \mathrm{~g})$ were powdered mechanically using commercial electrical stainless steel blender and extracted with hexane $(2,200 \mathrm{ml})$, ethyl acetate $(2,500 \mathrm{ml})$ and methanol $(2,800 \mathrm{ml})$, in a soxhlet apparatus (boiling point range $60-80^{\circ} \mathrm{C}$ ) for $6 \mathrm{~h}$. The extracts were filtered through a Buchner funnel with Whatman No. 1 filter paper. The extracts were concentrated under reduced pressure $22-26 \mathrm{~mm} \mathrm{Hg}$ at $45^{\circ} \mathrm{C}$ and the residue obtained was stored at $4^{\circ} \mathrm{C}$. The residues were then made in to a $1 \%$ stock solution with acetone (stock solution). From the stock solution, 1000-4.69 mg/, dilutions were prepared with dechlorinated tap water. Polysorbate 80 (Qualigens) was used as an emulsifier at the concentration of 0.05 per cent in the final test solution $[9,10]$.

\section{Mosquito Culture}

C. quinquefasciatus larvae were collected from rice field and stagnant water areas of Kura local government area of Kano state Nigeria and identified in department of biological sciences Yusuf Maitama Sule University, Kano State. Larvae were kept in plastic and enamel trays containing well water. They were maintained and all the experiments were carried out at $27 \pm$ $2^{\circ} \mathrm{C}$ and $75-85 \%$ relative humidity under $14: 10 \mathrm{~h}$ light and dark cycles. Larvae were fed a diet of Brewer's yeast, dog biscuits and algae collected from ponds in a ratio of 3:1:1, respectively as per the method of Kamaraj et al. [11].

\section{Mosquito Identification}

The filariasis vector larvae were identified by their simple morphological features as well as their behavior in water according to Linton et al. [12]. The larval head is short and stout, becoming darker toward the base. The mouth brushes have long yellow filaments that are used for filtering organic materials. The abdomen consists of eight segments, siphon, and saddle. Each segment has a unique setae pattern. The larvae of Culex mosquito tend to position themselves at an angle due to presence of siphon in which they use for respiration [13].

\section{Larval Bioassay}

During preliminary screening with the laboratory trial, the larvae of C. quinquefasciatus were collected from the insect-rearing cage and identified in Biological Department Yusuf Maitama Sule University, Kano. The larval bioassay was determined as per the procedure of WHO [14] and Rahuman et al [15]. Five batches of 20 larvae were used in each bioassay. Six different concentrations $(15.63,31.25,62,125,250$ and $500 \mathrm{ug} / \mathrm{mL})$ were papered with $100 \mathrm{~mL}$ dechlorinated tap water, in a separate plastic container. Polysorbate 80 was used as an emulsifier at the concentration of $0.05 \%$ in the final test solution. The control was set up with acetone, polysorbate 80 and dechlorinated tap water. The numbers of dead larvae were counted after $24 \mathrm{~h}$ of exposure and percentage of mortality was reported from the average of five replicates. The experimental media in which $100 \%$ mortality of larvae occurs alone were selected for dose-response bioassay [15].

\section{Dose-Response Bioassay}

The different concentrations ranging from 15.63 to $500 \mu \mathrm{g} / \mathrm{mL}$ were prepared. Based on the preliminary screening results, different solvents of leaf and bark extracts prepared from G. tricantha, A. indica, E. globulus and O. gratissimum were subjected to dose-response bioassay for larvicidal activity against the larvae of C. quinquefasciatus. The numbers of dead larvae were counted after $24 \mathrm{~h}$ of exposure, and the percentage of mortality was reported from the average of five replicates [15].

\section{Statistical Analysis}

The average larval mortality data were subjected to probit analysis for calculating $\mathrm{LC}_{50}, \mathrm{LC}_{90}$, and other statistics at 95\% confidence limits of upper confidence limit and lower confidence limit, and Chi-square values were calculated by using the software developed by Reddy et al. [16]. $\mathrm{P}<0.05$ was considered to be statistically significant.

\section{RESULT AND DISCUSSION}

Botanical phytochemicals with mosquitocidal potential are now recognized as potent alternative insecticides to replace synthetic insecticides in mosquito control programs due to their excellent larvicidal properties. In the present observation, hexane, ethyl acetate and methanol extract of leaf, and bark of G. tricanthos, A. indica, O. gratissimum and E. globulus extracts were tested against C. quinquefasciatus, mortality of four plant extracts were recorded, and the findings, related to the larvicidal activities of various plant extracts reported by the earlier authors corroborate the present study results [10].100\% larval mortality was observed in the bark methanol extract of A. indica, and G. triacanthos. Bark ethyl acetate and methanol extract of E. globulus and leaf ethyl acetate extract of O. gratissimum (Table 1). All plant extracts showed moderate toxic effect on C. quinquefasciatus after $24 \mathrm{~h}$ of exposure at $500 \mathrm{mg} /$; however, the highest mortality was found in leaf methanol extract of $O$. gratissimum, bark ethyl acetate extract of E. globulus, methanol bark extract of A. indica and lastly bark methanol extract of $G$. triacanthos against the larvae culex withLC ${ }_{50}=43.00,41.02,40.12$ and $20.36 \mathrm{mg} /$;

Table 1: Larvicidal activity of crude plant extracts against fourth instar larvae of Cx. quinquefasciatusat $500 \mathrm{ug} / \mathrm{mL}$ (Mean \pm SD) (\%)

\begin{tabular}{lccc}
\hline Botanical name & \multicolumn{3}{c}{ Mortality } \\
\cline { 2 - 4 } & Hexane & Ethylacetale & Methanol \\
\hline O.gratissimum & $83.00 \pm 2.15$ & $75.00 \pm 2.00$ & $100.00 \pm 0.00$ \\
E.globulus & $72.00 \pm 2.32$ & $100.00 \pm 0.00$ & $100.00 \pm 0.00$ \\
A.indica & $86.00 \pm 1.63$ & $75.00 \pm 3.21$ & $100.00 \pm 0.00$ \\
G.tricantha & $81.00 \pm 2.02$ & $89.00 \pm 2.01$ & $100.00 \pm 0.00$ \\
\hline
\end{tabular}

Control - Nil mortality 
Table 2: Larvicidal activity of different solvent crude extracts against fourth instar larvae of C. Quinquefasciatus

\begin{tabular}{|c|c|c|c|c|c|}
\hline \multirow[t]{2}{*}{ Plant extract } & \multirow[t]{2}{*}{ Solvents } & \multicolumn{2}{|c|}{$\mathrm{LD}_{50}$} & \multicolumn{2}{|c|}{$\mathrm{LD}_{90}$} \\
\hline & & Mean \pm SD & ULC- LCL & Mean \pm SD & ULC - LCL \\
\hline 0. gratissimum & Methanol & $43.00 \pm 3.52$ & $47.76-33.12$ & $278.32 \pm 19.11$ & $298.73-137.85$ \\
\hline E. globulus & Ethyl acetate & $41.02 \pm 2.82$ & $58.01-22.01$ & $218.72 \pm 16.01$ & $291.21-102.05$ \\
\hline A. indica & Methanol & $40.12 \pm 1.33$ & $58.00-21.76$ & $215.01 \pm 13.15$ & $268.31-192.10$ \\
\hline G. tricantha & Methanol & $20.36 \pm 1.42$ & $20.15-15.28$ & $86.29 \pm 12.18$ & $109.32-81.16$ \\
\hline
\end{tabular}

Control - Nil mortality; $L_{50}$ - Lethal concentration that kills 50 per cent of the exposed larvae; $L_{90^{\prime}}$ Lethal concentration that kills 90 per cent of the exposed larvae; $U C L$, upper confidence limit; $L C L$, lower confidence Limit; comparing experimental and control group, with a significance level established at $\mathrm{P}<0.05$ and were chi-square value was significant

$\mathrm{LC}_{90}=278.32,218.72,215.01$ and $86.29 \mathrm{mg} / \mathrm{l}$ respectively. The data obtained were analyzed using Chi-squared test, comparing experimental and control groups, with a significance level established at $\mathrm{P}<0.05$ (Table 2).

Crude extract of leaves or bark of the plants have been tested earlier by several investigators and larvicdal activities have been shown against C. quinquefasciatus [17-23]. The leaf of O. gratissimum show more effective repellents activity against the C. quinquefasciatus which is in accordance with the Rajkumar's findings [24]. The methanol extracts shows 100\% larval mortality at concentration of $500 \mathrm{ug} / \mathrm{mL}$ against C.quinquefasciatus is also in accordance with Rajkumar's finding [20].

In conclusion, the findings showed that leaf and bark extract of G. tricantha, A. indica, O. gratissimum and E. globulus can be developed as ecofriendly larvicides. Also the results open the possibility for further investigations of the efficacy of larvicidal properties of natural product extracts.

\section{REFERENCES}

1. WHO. Combating waterborne diseases at the household level Part1. WHO, Geneva. 2007, pp.36.

2. NICD. National Institute of Communicable Diseases: Proceedings of the National Seminar on operation research on vector control in filariasis. New Delhi. 1990.

3. Ahn, Y.J., Won, M.K., Park, H.M. and Han, C.G. Potent insecticidal activity of Ginkgo bilab-derived trilactoneterpenes against Nilaparvatalugens. $90-105$, in Phytochemicals for pest control, Eds. P.A. Hedin, R.M. Hollingworth, E.P. Masler, J. Miyamoto and D.G. Thompson. 1997.

4. Geetha, I.. Paily, K.P., Padmanaban, V. and Balaraman, K.Oviposition response of the mosquito, Culexquinquefasciatus to the secondary metabolite(s) of the fungus, Trichodermaviride. Mem Inst Oswaldo Cruz, 2003;98: 223-226.

5. Sukumar, K., Perich, M.J. and Boobar, L.R.Botanical derivatives in mosquito control: a review. Journal of American Mosquito Control Association, 1991;7:210-237.

6. Prajapati, V., Tripathi, A.K., Aggarwal, K.K. and Khanuja, S.P.S. Insecticidal, repellent and oviposition- deterrent activity of selected essential oils against Anopheles stephensi, Aedesa egypti and Culex quinquefasciatus. Bioresources Technology, 2005;96:1749-1757.

7. Ramkumar, G., Karthi, S., Muthusamy, R., Natarajan, D. and Shivakumar, M.S. Adulticidal and smoke toxicity of Cipadessabaccifera (Roth) plant extracts against Anopheles stephensi, Aedesaegypti, and Culexquinquefasciatus. Parasitology Research, 2014;41:73-5.

8. Kokwaro, J.O.Medicinal plants of East Africa Nairobi, Kenia. East Africa Publishing Bureau, 1980;111pp.

9. Mehra, B.K. and Hiradhar, P.K. Effect of crude acetone extract of seeds of Annonasquamosa Linn. (Family: Annonaceae) on possible control potential against larvae of Culexquinquefasciatus Say. J Entomol Res., 2000;24:141-6.

10. Kamaraj, C., Bagavan, A., Rahuman, A.A., Zahir, A.A., Elango, G. and Pandiyan, G. Larvicidal potential of medicinal plant extracts against Anopheles subpictusGrassi and Culextritaeniorhynchus Giles (Diptera: Culicidae). Parasitol Res., 2009;104:1163-71.

11. Kamaraj, C., Abdul Rahman, A., Bagavan, A., Abduz Zahir A., Elango, G. and Kandan, P. Larvicidal efficacy of medicinal plant extracts against Anopheles stephensi and Culex quinquefasciatus (Diptera: Culicidae). Trop Biomed., 2010;27:211-19.

12. Linton, Y. M., Harbach, R. E., Chang, M.S., Anthony T.G. and Matusop A. MophologicalandMolecular identity of anopheles (Diptera: culicidae) the nominotypical member of a malaria vector species complex in south Asia. Systentomol., 2001;26:357-366.

13. Sirivanakarn, S. and White, G. B. Neotype designation of Culex quinquefasciatus Say (Diptera: Culicidae). Proceedings of the Entomological Society of Washington 1978;80:360-372.

14. World Health Organization. Report of the WHO informal consultation on the evaluation on the testing of insecticides, CTDNHO PES/ IC/96.1. Geneva: WHO; 1996; p. 69.

15. Rahuman, A.A., Gopalakrishnan, G., Ghouse, B.S. and Arumugam, S. Himalayan B. Effect of Feronialimonia on mosquito larvae. Fitoterapia, 2000;71:553-5.

16. Reddy, P.J., Krishna, D., Murthy, U.S. and Jamil, K.A microcomputer FORTRAN program for rapid determination of lethal concentration of biocides in mosquito control. CABIOS, 1992;8:209-213.

17. Kihampa, C., Joseph, C.C., Nkunya, M.H., Magesa,S.M., Hassanali, A. and Heydenreich, M. Larvicidal and IGR activity of extract of Tanzanian plants against malaria vector mosquitoes. J Vector Borne Dis. 2009;46:145-52.

18. Saxena, R.C., Harshan, V., Saxena, A., Sukumaran, P., Sharma, M.C. and Kumar, M.L. Larvicidal and chemosterilant activity of Annonasquamosa alkaloids against Anopheles stephensi. J Am Mosq Control Assoc, 1993;9:84-7

19. Bagavan, A., Kamaraj, C., Abdul Rahuman, A., Elango, G., Abduz Zahir, A. and Pandiyan, G. Evaluation of larvicidal and nymphicidal potential of plant extracts against Anopheles subpictusGrassi, Culextritaeniorhynchus Giles and Aphis gossypii Glover Parasitol Res., 2009;104:1109-17.

20. Elango G, Rahuman AA, Kamaraj C, Bagavan A, Zahir AA. Screening for feeding deterrent activity of herbal extracts against the larvae of malaria vector Anopheles subpictus Grassi. Parasitol Res. In press 2011.

21. Kamaraj, C., Kaushik, N.K., Mohanakrishnan, D., Elango, G., Bagavan, A. and Zahir, A.A. Antiplasmodial potential of medicinal plant extracts from Malaiyur and Javadhu hills of South India. Parasitol Res., 2011; 111(2): 703-5.

22. Saxena, R.C., Dixit, O.P. and Sukumaran, P. Laboratory assessment of indigenous plant extracts for anti-juvenile hormone activity in Culexquinquefasciatus. Indian J Med Res, 1992;95:204-6.

23. Haouas, D., B.H.Kamel, M., Harzallah, F.S. and Ben Hammouda, M.H. Bioactivities of seven chrysanthemum species flowers powder on Spodopteralittoralis (Boiduval) larvae. Commun Agric Appl BiolSci., 2005;70:799-807.

24. Rajkumar, S. and Jebanesan, A.Repellent activity of selected plant essential oils against the malarial fever mosquito Anopheles stephensi. Trop Biomed., 2007;2:71-5. 